\title{
Fjernsynsdiskursens indkodning og afkodning: introduktion til en klassiker
}

\author{
Kim Schrøder
}

MedieKultur 2015, 58, 124-130

Published by SMID | Society of Media researchers In Denmark | www.smid.dk

The online version of this text can be found open access at www.mediekultur.dk

Stuart Halls artikel "Fjernsynsdiskursens indkodning og afkodning" (1973) er for længst blevet optaget i den internationale kommunikationsforsknings Hall of Fame. Det skete officielt i 2003, da den var én af de historiske publikationer, der blev gjort til genstand for kanonisering i bogen Canonic Texts in Media Research. Are There Any? Should There Be? How About These? af Elihu Katz og en gruppe kolleger. Halls artikel er her i fint - og fortjent - selskab med bl.a. Theodor W. Adorno \& Max Horkheimers essay om kulturindustrien og Marshall McLuhans Understanding Media. Optagelsen blev motiveret af Michael Gurevitch og Paddy Scannell, der udnævnte den til at være "den genfødte modtagerforsknings urtekst" (Gurevitch \& Scannell, 2003, p. 241).

Artiklen havde da i flere årtier været den grundlæggende inspirationskilde for den voksende receptionsanalytiske tradition, hvis udøvere næsten rituelt altid har en reference til Halls "banebrydende artikel". Mærkeligt nok er denne reference meget ofte til artiklens 1980-udgave, der er en betydeligt forkortet version af den originale tekst fra 1973. Det vil sige, så mærkeligt er det måske ikke, eftersom 1973-versionen først blev udgivet på engelsk i 2007 (Gray m.fl., 2007)

Når det i 2015 er berettiget at offentliggøre en oversat version af 1973-artiklen, er det fordi fremtidige brugere af artiklen dermed kan få en dybere videnskabshistorisk forankring og forståelse af Halls ræsonnement. Det er nemlig betydeligt bredere, end man får indtryk af ud fra 1980-udgaven, der hovedsageligt beskæftiger sig med de tre læsningsmåder, som seere (og mediebrugere i det hele taget) kan benytte sig af i mødet med en mediediskurs: 
dominerende, forhandlede og oppositionelle læsninger. Det, artiklen er blevet husket for, og reduceret til, er således artiklens sidste fire sider, der handler om 'afkodning', og det er først med David Deacons et al.'s rehabilitering af 'indkodningen' (Deacon et al., 1999), at Halls oprindelige, holistiske teoretiske intervention igen blev taget alvorligt.

\section{Artiklens videnskabshistoriske positionering}

Artiklen lagde grunden til og sammenfattede i en nøddeskal tre teoretiske grundpositioner, der efterfølgende blev videreudviklet inden for kulturvidenskaben i de følgende årtier, og som stadig har videnskabelig validitet. Det drejer sig om tre indbyrdes forbundne grundpositioner: For det første argumenterer Hall for, at kommunikationsvidenskab må anskues som et holistisk projekt, hvor forskerne må definere og operationalisere deres forskningsmål på en måde, der medtænker totaliteten af de aktører, kontekster og processer, der indgår i det kommunikative forløb fra afsendere til modtagere. For det andet skal det kommunikative forløb forstås inden for rammerne af en socialsemiotisk tegnteori, som en betydningsdannende diskursiv proces. Og for det tredje skal kommunikationsforskningen analysere den situationelle og sociokulturelle kontekst $\mathrm{i}$ bredest mulig forstand som medskabende $\mathrm{i}$ den kommunikative proces. Især på dette tredje punkt vedkendte Hall sig sin gæld til den samtidige engelske kulturteoretiker Raymond Williams $(1958 ; 1961)$ og trak på hans teori om kultur som en hel livsform. Hall udtrykker i artiklen et forsigtigt håb om, at artiklen kan være med til at bane vejen for et nyt paradigme inden for medie- og kommunikationsforskningen: "Man har før inden for kommunikationsforskningen talt om, at en æra begynder eller slutter. Så derfor skal man træde varsomt. Men der ser ud til at være et vist grundlag for at tro, at en ny og spændende fase i modtagerforskningen er ved at åbne sig. Ved begge ender af den kommunikative proces er der udsigt til, at brugen af det semiotiske paradigme kan fortrænge den hårdnakkede behaviorisme, der har plaget medieforskningen i så mange år." (s. 135).

Hans indkodning-/afkodningsmodel var et bevidst forsøg på at støde det 'dominerende paradigme' (Gitlin, 1978) fra tronen, dvs. den anglo-amerikanske samfundsvidenskabelige, positivistiske tilgang til kommunikationsforskning, der havde målingen af medie-effekter som et af sine hovedformål, og som havde domineret kommunikationsforskningen siden 1920'erne. Men hans teoretiske argumentation var også rettet imod det dominerende paradigme inden for den humanistiske litteraturanalyse, som var forankret i den opfattelse, at man gennem tekstanalyse af litterære værker kunne nå frem til sand viden om tekstens mening. I forlængelse heraf var artiklen også tænkt som et alternativ til den form for kulturanalyse, der - som det var tilfældet med Frankfurterskolens ideologikritik - anså tekster for at rumme en undertrykkende ideologisk betydning, der satte sig direkte igennem som en uimodståelig 'effekt' på underklassens kollektive bevidsthed.

Endelig var Halls artikel gennemsyret af en marxistisk politisk dagsorden, som var meget typisk for human- og samfundsvidenskabelige miljøer i 1960'erne og 1970'erne. Men inden 
for den marxistiske orientering indtog Hall, sammen med Williams og andre, en position der tillagde samfundets kulturelle sfære en relativt autonom rolle, i modsætning til de marxister, der anså samfundets økonomiske og klassemæssige 'basis-strukturer' for at have en determinerende rolle i forhold til den politiske og kulturelle 'overbygning'. Med sprogbrugen fra Halls tre receptionsformer kan man sige, at de ortodokse marxister kun anerkendte eksistensen af 'dominerende' læsninger, mens Hall plæderede for, at der også kunne tænkes 'forhandlede' og 'oppositionelle' læsninger af medieindhold (se også Schrøder, 2013).

\section{Mediebrugernes relative autonomi}

Halls argumentation for relationerne mellem afsender, budskab og modtagelse er meget kompleks, til tider decideret knudret, når han på den ene side vil tilkende mediebudskabet/ teksten en bestemmende rolle og samtidig vil argumentere for, at produktion og reception også er afgørende 'momenter' i medietekstens kommunikative kredsløb. Der er her tale om et betydningsteoretisk paradoks, der ikke endeligt kan afklares teoretisk. Det banebrydende ved Halls løsningsforsøg er, at han teoretisk både fastholder og negerer paradokset, men gør det gennem et begrebsapparat, der lægger afgørelsen over til empiriske undersøgelser af modtagernes faktiske aktualisering af medieteksten. Hall mente selv, at hans teoretiske models vellykkethed stod og faldt med en sådan empirisk afprøvning af begreber og positioner, således som den nogle år senere blev gennemført i David Morleys receptionsundersøgelse af BBC-aktualitetsprogrammet Nationwide (Morley, 1980).

Det teoretiske begreb, der fastholder det spændingsfyldte paradoks om den samtidige tilstedeværelse af medietekstens betydningsmæssige og ideologiske dominans, og af mediebrugernes relative autonomi til at afkode medietekstens betydning, er begrebet 'foretrukken betydning', eller 'foretrukken læsning'. Kommunikationens mangetydighed kan altså både lokaliseres i medieteksten selv og i modtagerens aktualisering af medieteksten. Medietekstens foretrukne betydning er et produkt af indkodningsprocessen, som Hall især beskriver indgående i sin analyse af westerngenren, som er udeladt i 1980-versionen.

Den del af artiklen, der handler om betydningen af voldshandlinger i fiktion, specifikt westerns, har til formål at beskrive den grundlæggende strukturalistiske tankegang, der er drivkraften i hele artiklens ræsonnement: dvs. at de enkelte delelementers betydning $i$ en diskurs får betydning i relation til de øvrige delelementer. Pointen er, at selv i en så regel- og konventionsbundet genre som westernfilmen, der i kraft af disse konventioner lægger op til en klar 'foretrukken betydning', er det enkelte handlingselement semiotisk set mangetydigt (polysemisk). I forhold til voldsproblematikken er pointen her, at den vold, helten begår i en western, ikke betyder 'vold', men 'maskulin handlekraft', og at man derfor ikke behøver at være bekymret for, at westernseerne bliver inspireret til voldelig adfærd af at se westerns.

Det er gørende for ræsonnementets teoretiske pointe, at en western ikke har en foretrukken betydning. Men westerndiskursens konkrete indkodning (eller 'artikulation') i den 
specifikke film lagger op til en 'foretrukken betydning' (på engelsk: "a preferred meaning is suggested"). I dette ræsonnement er vi endda ikke nået til overhovedet at tale om modtagernes reception af westernfilmens tegnkompleks: Det er allerede inden for tekstens tegnstruktur, at der opstår en mangetydig mening, der "befinde[r] sig på et kontinuum, der går fra dominerende til underordnet".

I næste moment forstærkes tekstens mangetydighed så, når modtageren afkoder teksten: "[...] dette har selvfølgelig konsekvenser for receptionsenden af den kommunikative kæde: Der kan ikke opstilles nogen lov, der sikrer, at modtageren opfatter en voldshandlings foretrukne eller dominerende betydning på præcist samme måde, som den er blevet indkodet af producenten." (s. 10).

Samme ræsonnement forfølger Hall derefter inden for TV-faktagenrer: Han bestemmer (nyheds)medieteksten som - $\mathrm{i}$ kraft af den historiske arv af betydninger og samfundseliters magt over indkodningsprocessen - nødvendigvis bærende på en 'foretrukken betydning'. Men den foretrukne betydning er 'kun' foretrukken, den bestemmer ikke modtagerens aktualisering: "Vi kalder det dominerende, ikke 'bestemmende', fordi det altid er muligt at ordne, klassificere, tildele og afkode en begivenhed på mere end ét 'kort'. Men vi kalder det også 'dominerende', fordi der eksisterer et mønster af 'foretrukne læsninger', dvs. nogle kort som både har den institutionelle, politiske og ideologiske orden indskrevet i sig, og som selv bliver institutionaliseret" (s. 142-143). Men de foretrukne læsninger møder så kommunikationens modtagere på en måde, hvor de - fordi der kan være en manglende overensstemmelse mellem indkodernes og afkodernes koder - har en relativ autonomi til at overtage, forhandle eller modsætte sig den foretrukne betydning.

\section{Artiklens anledning}

1980-udgaven af artiklen er dekontekstualiseret i den forstand, at den her fremstår som et isoleret manifest, som Halls bidrag til bogen Culture, Media, Language, som præsenterede nogle af de forskningsprojekter, som Mediegruppen ved Centre for Contemporary Cultural Studies havde gennemført sidst i 1970'erne. I 1973-versionen præsenteres den som Halls bidrag til et kollokvium om kritisk mediepædagogik, der blev afholdt ved The Centre for Mass Communication Research, University of Leicester, i regi af Europarådet og med centrets leder James Halloran som vært.

Hall og Birminghamfolkene var i opposition til forskningsmiljøet i Leicester, fordi de anså det for at være den lokale britiske repræsentant for det dominerende, nordamerikanske, positivistiske paradigme inden for medieforskningen. I et interview i 1994 beskrev Hall sit indlæg på kollokviet som "polemisk". Leicester-miljøet:

var et traditionelt center, der brugte traditionelle positivistisk-empiriske modeller til indholdsanalyse, modtagereffekter, spørgeskemaundersøgelser, osv. Så mit paper [...] havde et lettere polemisk sigte. Det positionerer sig op imod nogle af disse positioner, [...] og imod 
den specielle opfattelse, at indholdet har en fastlagt betydning som budskab (Cruz \& Lewis, 1994, 253).

I tilbageblik fra 2015 kan man måske sige, at Halloran og hans forskningsmiljø tjente som en form for bekvem lokal stedfortræder for langt mere positivistiske og empiricistiske amerikanske kommunikationsforskere, som man kunne formulere det nye kulturforskningsparadigme op imod. Halloran - som Hall i øvrigt omtalte som "god ven" (Hall, 2013, p. 770) - kritiserede eksplicit nordamerikansk effektforskning for at være ateoretisk og overdrevent kvantitativ, og talte for en forskningsdagsorden der på mange måder mindede om Halls (Halloran, 1970, p. 15).

Når Hall alligevel italesatte sit kollokviebidrag som et polemisk angreb på Leicesterskolen, vidner det om indædtheden i de politiske modsætninger i samfundsvidenskabelige og humanistiske miljøer i 1970'erne. I Birminghamskolens øjne var det utilgiveligt, at Leicesterfolkenes forskning havde et funktionalistisk præg, hvor man gav udtryk for, at forskere havde "en pligt til at bidrage til løsningen af samfundsmæssige problemer" (Halloran, 1970, p. 21), i stedet for grundlæggende at kritisere den kapitalistiske samfundsform, der var skyld i de samfundsmæssige problemer, som det britiske samfund stod overfor (Gurevitch \& Scannell, 2003).

\section{Artiklens fremtrædelse: "stencileret arbejdspapir"}

De første syv år af artiklens liv, indtil publiceringen i forkortet udgave i 1980 (Hall et al., 1980) foregik som stencileret arbejdspapir, dvs. en tekst skrevet på skrivemaskine på en papirskabelon med udstansede huller, der derefter kan mangfoldiggøres på en duplikator. Det var indtil midten af 1970'erne den form, hvori kulturstudiecentret i Birmingham offentliggjorde mange af de banebrydende arbejder, der udsprang af det frodige, nytænkende og kaotiske forskningsmiljø. Andre bidrag blev publiceret i skriftserien Cultural Studies, indtil centret indgik en aftale med Hutchinson-forlaget om at udgive artikler i antologier ( $\mathrm{fx}$ Hall \& Jefferson, 1975).

Ud over det polemiske og teoriudviklende sigte kan artiklen i nogle passager også ses som en form for indføring i semiologisk og semiotisk tegnteori. Inden for kulturteori og -analyse var semiologi/semiotik på det tidspunkt det nyeste nye, som Hall ikke kunne tage for givet, at læserne var bekendt med, fx de grundlæggende mekanikker mellem udtryk og indhold, og mellem de semiotiske tegntyper ikon, indeks og symbol. Som læser kan man ikke undgå at lægge mærke til de mange anførselstegn, som Hall sætter om ord og begreber som 'sprog', 'fjernsynssprog', 'brug', 'budskab', 'produkt', osv. De vidner om, at Birminghamskolens kulturanalytiske projekt på dette tidspunkt var i gang med en omfattende definitorisk øvelse, hvor dagligsprogets ord og traditionelle kulturteoretiske ord blev udsat for omfortolkning for at kunne indgå i nye teoribygninger. Et af kollokviets temaer var således 'fjernsynssprogets beskaffenhed' ('nature'), hvor fjernsynssproget sættes i anførselstegn: man var på det tidspunkt stærkt optaget af at diskutere, om og hvordan der var andre udtryksformer end verbalsproget, der kunne beskrives videnskabeligt på samme måde som 
verbalsproget ( $\mathrm{fx}$ Christian Metz om filmens syntaks; Roland Barthes om billedets retorik, osv.). Få år senere udgav de to CCCS-disciple John Fiske og John Hartley bogen Reading Television (1978), hvis danske oversættelse, Fjernsynets sprog (1981), satte fokus på den forudsætning i den engelske titel, at fjernsynet kommunikerede gennem et sprog. Tilsvarende var det i artiklen magtpåliggende for Hall at få læserne til at forstå, at massemediernes kommunikative 'produkt' nok var beslægtet med de generelle materielle produkter, som frembringes i kapitalistiske produktionsprocesser, men at det samtidig var unikt, fordi det blev frembragt af 'materialer' som sproglige og visuelle tegn, der medbragte langsigtede repræsentationsmæssige og ideologiske implikationer af betydning for hele samfundsstrukturens reproduktion.

\section{Hall-modellens begrænsninger}

Som beskrevet ovenfor i denne korte introduktion har Halls 1973-artikel på mange måder været banebrydende, især for receptionsforskningen, men også for medie- og kulturforskningen i bredere forstand. Hall selv havde ikke forestillet sig, at indkodning/afkodningmodellen ville vinde stor udbredelse: "Indkodning/afkodning-modellen var ikke tænkt som en banebrydende model. Jeg havde ikke forestillet mig, at den ville holde til de næste 25 års forskning, Dertil har den ikke tilstrækkelig teoretisk stringens, intern logik og begrebsmæssig konsekvens" (Hall i Cruz \& Lewis, 1994, p. 255).

Der har fra forskellig side været fremført kritik af Halls teoretiske model. Således har det af forskere fra den marxistisk inspirerede politisk-økonomiske medieforskning været fremført, at receptionsanalysens brug af modellen har været præget af en vis naivitet omkring mediebrugernes muligheder for at modsætte sig den samfundsbevarende ideologiske kraft, som medie- og kulturindustrien besidder (Ferguson et al., 1997).

Også forskerne bag kanoniseringen af Halls artikel peger på nogle problemer, specielt vanskeligheden med at operationalisere de centrale begreber: De fremhæver således, at påstanden om, "at der er bygget en foretrukken læsning ind $\mathrm{i}$ teksten, kan være analytisk attraktiv, men den er ikke let at teste empirisk. [...] Mere generelt, i en polysemisk verden så bliver en håndfast klassificering af indkodning og afkodning temmelig vanskelig at opretholde" (Gurevitch \& Scannell, 2003, p. 245).

I forlængelse heraf kan man sige, at modellen er for éndimensional i sin fokusering på de semiotisk-politiske aspekter af medieret betydningsdannelse til at kunne anvendes som teoretisk grundlag for analyse af de komplekse, multidimensionale betydningsprocesser, som mediebrugere indgår i (Schrøder, 2000/2003; Michelle, 2007). Endelig har modellen i en tid, hvor mediebrugerne i stigende grad ikke bare 'læser' medieindhold, men i stigende grad tager aktivt del i mediernes betydningsproduktion, en begrænsning i udelukkende at omhandle receptive processer.

Ikke desto mindre må man sige, at Hall havde ret, da han i 1973 forsigtigt dristede sig til at forudsige, at "en ny og spændende fase i modtagerforskningen" var ved at åbne sig. 
Hans stencilerede artikel om indkodning og afkodning af fernsynsdiskurser var en vigtig drivkraft i den udvikling.

\section{Referencer}

Cruz, J. \& Lewis, J. (1994). Reflections upon the encoding/decoding model: An interview with Stuart Hall. I Cruz, J. \& Lewis, J., Viewing, reading, listening. Boulder, CO: Westview Press.

Deacon, David, Fenton, Natalie \& Bryman, Alan (1999). From inception to reception: The natural history of a news item. Media, culture \& society 21, 5-31.

Ferguson, Marjorie \& Golding, Peter (Eds.) (1997). Cultural studies in question, London: Sage.

Fiske, John \& Hartley, John (1978). Reading television, London: Methuen. Oversat til dansk af Kim Schrøder: Fjernsynets Sprog (1981), København: Nyt Nordisk Forlag Arnold Busck.

Gitlin, Todd (1978). Media sociology: the dominant paradigm. Theory and society 6, 205-253.

Gray, Ann, Campbell J., Erickson, Mark, Hanson, Stuart, \& Wood, Helen (Eds.), (2007). CCCS Selected Working Papers, vol. 2, New York: Routledge.

Gurevitch, Michael \& Scannell, Paddy (2003). Canonization achieved? Stuart Hall's “Encoding/Decoding”. I Elihu Katz, John D. Peters, Tamar Liebes og Avril Orloff (Eds.), Canonic texts in media research. Are there any? Should there be? How about these?, Cambridge: Polity Press.

Hall, Stuart (2013). Stuart Hall Interview, 2 June 2011 (interviewer: Hudson Vincent). Cultural Studies, vol. 27, nr. 5, 757-777.

Hall, Stuart \& Jefferson, Tony (Eds.), (1975). Resistance through rituals. London: Hutchinson.

Hall, Stuart, Hobson, Dorothy, Lowe, Andrew \& Willis, Paul (Eds.), (1980). Culture, media, language. London: Hutchinson.

Halloran, James (Ed.), (1970). The effects of television. London: Panther.

Michelle, Carolyn (2007). Modes of reception: A consolidated analytical framework. The Communication Review, 10 (3), 181-222.

Morley, David (1980). The 'Nationwide' audience. London: British Film Institute.

Schrøder, Kim Christian (2000). Making Sense of Audience Discourses: Towards a Multidimensional Model of Mass Media Reception. European Journal of Cultural Studies, vol.3, no.2: 233-258. Dansk revideret udgave: "Generelle aspekter ved mediereception? - Et bud på en multidimensional model for analyse af kvalitative receptionsinterviews". MedieKultur nr. 35, 63-73, 2003.

Schrøder, Kim Christian (2013). Socio-cultural models of communication. I Paul Cobley \& Peter J. Schultz (Eds.). Theories and Models of Communication, Berlin/Boston: Mouton de Gruyter.

Williams, Raymond (1958). Culture and society. London: Chatto and Windus.

Williams, Raymond (1961). The long revolution. London: Chatto and Windus. Paperback udg. Pelican Books 1965.

Kim Schrøder

Professor

Department of Communication, Business and Information Technologies

Roskilde University, Denmark

kimsc@ruc.dk 